\title{
Risky Sexual Behaviour and Predisposing Factors to HIVISTI Among Students in Mizan-Tepi University (A Case of Tepi Campus)
}

\author{
Sefawdin Berta Bedassa \\ Department of Biology, Mizan-Tepi University, Tepi, Ethiopia
}

\section{Email address:}

nebilsefa@gmail.com

To cite this article:

Sefawdin Berta Bedassa. Risky Sexual Behaviour and Predisposing Factors to HIV/STI Among Students in Mizan-Tepi University (A Case of Tepi Campus). Science Journal of Public Health. Vol. 3, No. 5, 2015, pp. 605-611. doi: 10.11648/j.sjph.20150305.12

\begin{abstract}
Students of higher institutions are assumed to have risky sexual behaviour that exposed to HIV infection. This study aimed to identify imperative information on Sexual risky behavior and Pre-exposing factors to have multiple sexual partners among Mizan-Tepi University students in Ethiopia in order to design an intervention method. Institution based Crosssectional study was conducted from April to May 2015. Both qualitative and quantitative study was conducted among 808 students. The data were collected using self-administered questionnaire and analysed using SPSS V.16.0. 306 (37.9\%) students ever had sex and 168(63.36\%) of them had in campus. Among whoever had sex, 37.9\% had sex in the last 12 months, $28.3 \%$ had multiple sexual partners, 211(69.4\%) not used condom consistently, 110(36.9\%) have sexual partner out of campus, 214(71.1\%) were attend night dance group and 539(66.71\%) used substance. Students that view Pornography, use substances and attend night group dance were $2.8(\mathrm{OR}, 95 \% \mathrm{CI}, 2.801$ (1.658-4.730), 1.5 times (OR, 95\% $\mathrm{CI}, 1.502(.865-2.609)$ and 1.3 times (OR, 95\%CI, 1.301(.787-2.152) more likely to have multiple sexual partner respectively. Among respondents who perceive the risk of HIV in the campus reduce the likely hood to have multiple sexual partners by 0.7 (OR, $95 \% \mathrm{CI}$; $0.686(0.809-0.517)$ and having multiple sexual partner reduce the probability of using condom by half $(0.5)$ unit (OR, $95 \% \mathrm{CI}$, $0.517(.295-.904)$ at $\mathrm{P}<0.05$. Substance use, sexual partner, living out of campus, shisha use, night group dance and STD history were identified as predisposing factors to risky sexual behaviour. The study revealed serious risky sexual behaviors and predisposing factors among the students, which may expose them to HIV. The universities should review the existing curriculum to integrate or separately develop as a course which can be taken as sex education and HIV/STD, and provide special attention to female students' life skill training.
\end{abstract}

Keywords: Risky Behaviour, Mizan-Tepi University, University Students, Predisposing Factors

\section{Introduction}

Most university students are adolescents and young adults, a group often characterized by a new-found sense selfgovernment, experimentation with sex and sometimes drugs and a feeling of invincibility [1]. Nearly $50 \%$ of the global population is less than 25 years old and $90 \%$ of them lives in developing countries. In Sub-Saharan Africa youths constitute $20-30 \%$ of the population [2]. Ethiopia is the second most populous nation in Africa. About $84 \%$ of the population lives in rural areas, and one-fifth are aged 15-24 years [3]. Risky behaviours may further be worsened by the fact that university students are too many in number, live away from their parents and free from parental control. Beside, some are subjected to wide spread substance use and peer-pressure that aggravate the risky behaviours. They are exposed to many risky behaviours including sexual coercion, STI including HIV/AIDS and abortion like other youths. Groups of people who engage in these high-risk behaviours are considered vulnerable to HIV infection need high care in order to control its epidemic[4] Prevention efforts in stopping the spread should focus on addressing gaps in programs and services and intensify efforts to reach the most at risk and vulnerable university students. These efforts should also target many of the behaviour-related risk factors for the epidemic in this country including, having multiple and coexisting partnerships, having sex at a young age, lack of consistent and proper condom use. Unless appropriate age and institution-targeted intervention exist, certain behaviours can place the university students at greater risk of HIV 
infection. The face of the government should turn to the elementary and high school, as they are in the youth age category and are in risky sexual behaviour. Thus, this study was conducted with the aim of filling this gap by identifying risky sexual behaviours and predisposing factors for possible interventions.

Higher education institutions in Ethiopia host young people aged between $18-24$ years. This age group is often sexually active and among the most vulnerable and at risk of HIV infection. Factors including lack of parental control, age, exposure to new environment, surrounding hotspots, peer pressure, cultural differences and lack of adequate information greatly contribute to the increased risk of these young people to the epidemic of HIV. Several studies documented the presence of high risk sexual behaviors among youth in higher education institutions in Ethiopia, which might put them at high risk of HIV infection and other sexual and reproductive health (SRH) complications. During the transition to university, young people face lots of new sources of stress, including separation from family, the formation of new social groups, intense academic pressures and the balancing of social activities with academic and other life responsibilities [5]. "The study done among university undergraduate students about sexual initiation and associated factors is very important, because of the fact that university students are many in number, live away from their parents and free from parental control"[6]. Some studies have shown common predisposing factors comprising risk factors known as the drivers of HIV/AIDS that expose individuals to risky sexual behaviour and HIV infection [7, 8]. A study conducted among Dilla University under graduate students identified unprotected sex, sexual experimentation on the campus and out-off campus, and multiple sexual partnerships as high risky sexual behaviours [9].

\subsection{Sexual Practice and Partners}

Research conducted on students in Jimma university showed, above quarter, 267(26.9\%) of respondents ever had sexual intercourse, among them (32.5\%) of them males and $12.7 \%$ of them were Females. Male respondents were found three times more likely to ever had sexual intercourse as compared to females [10]. It also indicated $121(75.6 \%)$ were had their first sexual intercourse during their secondary school. Research conducted at Wollaga University [11], on Jimma University students $[12,10]$ indicated $50.2 \%, 28.9 \%$ and $43.7 \%$ students reported to had ever had two or more life time sexual partners.

\subsection{Substance Use}

The use of alcohol, tobacco and other substances identified as one of the most important risk-factors among youngsters in secondary schools and colleges with consequent physical difficulties [13]. A study done among Addis Ababa University Undergraduate Students, 308(40.3\%), 23\% and $6 \%$ were used local alcoholic drinks, chewed khat and smoked cigarette respectively [6]. Jimma University students used to attend nightclub had two times more likely to ever have sexual intercourse as compared to non-attendants [10].

\section{Materials and Methods}

\subsection{Study Area and Period}

The study was conducted in Mizan-Tepi University (Tepi campus) undergraduate students from April to June $2014 / 2015$. The university have two campuses which are located in Mizan (Benchi maji zone) and Tepi Tawn (Sheka Zone), SW of Ethiopia. Tepi Camus is located $611 \mathrm{~km}$ from the capital city of Ethiopia, Addis Ababa. Currently, there are more than 34 universities in the country in which Mizan-Tepi University is among them. The Campus alone compresses two collages, one school and 14 departments in the study year $(2014 / 15)$.

\subsection{Study Design, Method and Population}

A cross sectional institution based study design and a quantitative and qualitative method of data collection was employed. The assessment mainly depended on primary data collection method and used semi-structured questionnaire. The total number of the study participants for each selected college or schools was obtained from the registrar and alumni directorate office. Full time undergraduate students ranging from year I to year $\mathrm{V}$ compressing all departments and groups in the department were included in the study. The total population in the study period from year one to year five was 3,412 . Among them 2,220 and 1,192 were male and female respectively.

\subsection{Sampling Technique}

Students were stratified based on year of study and total size population for females and males in each year was determined using single population proportion formula written here under. Then, samples were selected from respected departments and group of the department in that year using simple random sampling technique. The number allocated to females and males students in each year was again allocated to each department and then to each group of the department under the year of study using equal proportion question. FGDs was conducted among students who were thought to be informative. They were selected purposively to have supportive data for quantitative one. University anti-HIV club committees, non-café and nondormitory students, sex and year of study were considered for segmenting students for the FGDs. The guideline was aimed at collecting information on risky sexual behaviour of students and predisposing factors.

\subsection{Sample Size Determination}

The sample size was determined using single population proportion formula for the strata formed and equal proportion question assuming for department and groups. 50\% expected prevalence of risks for STIs/HIV infection, 95\% confidence 
level and 5\% level of accuracy were considered.10\% of the calculated sample size was added for non-response questioners and return with incomplete or spoiled questionnaires. In this study a total of 965 (328 female and 637 male) students were involved. The Final sample size required for the study was calculated using the following formula

$$
n o=\frac{\mathrm{Z}^{2} \mathrm{pq}}{e 2}
$$

Where $\mathrm{n}_{0}$ is the sample size, $\mathrm{Z}^{2}=(1.96)^{2}$ is desired confidence level $(95 \%), p$ is the estimated proportion of an attribute that is present in the population, and $\mathrm{q}$ is equals to $\mathrm{P}=0.5$ and e margin of error $(0.05)^{2}$ and;

$$
n=\frac{\mathrm{N}}{1+\mathrm{N} / \mathrm{no}}
$$

$\mathrm{n}=$ sample size, $\mathrm{N}=$ Total population and $\mathrm{e}^{2}=$ margin of error $(0.05)^{2}$

Sample size for each year determined separately and the sum was taken as total sample of the study.

\subsection{Data Collection}

A quantitative data was collected using self-administered questionnaire.The Dichotomous question was used for compel respondents to come off the fence on an issue and to gate a clear unequivocal response. The questionnaire was prepared in English and administered to selected students by data collectors and respected anti-HIV committee to reduce the non-return of the questioners and to avoid carelessness of students. Focus group discussions (FGDs) were conducted using guiding questions followed by predictable questioning. The researcher was moderated female's group and male groups in different way.

\subsection{Data Entry and Analysis}

After data collected, responses were coded and data were analyzed using SPSS version 16. Descriptive (frequencies) statistics was computed to determine the magnitude of STIs/HIV infection risks. Cross-tabulation and correlation analysis was carried out to gain more specific information about the relationship between these two variables. The quantification of the study findings reflect only the institutional level responses; however the qualitative study findings generated from each discussant are not compiled to reflect the collective responses of focus group. Bivariate logistic regression analysis was done and variables with pvalue less than 0.05 were included in the multiple logistic regression analysis. Odds ratio and 95\% confidence intervals were used to predict Risk probability. Findings obtained from discussants used to compliment the institutional/campus level results.

\subsection{Limitations of the Assessment}

The interest, carelessness, loss in accountability of students selected to this research, poor response and completeness of the information made available to the data collection teams.

\section{Result}

\subsection{Descriptive Findings}

\subsubsection{Sexual Behaviors of the Respondents}

965 students were expected but only 808 students participated in the study with the response rate of $89.8 \% .346$ $(42.8 \%)$ females and $462(57.2 \%)$ males, a total of 808 respondents were involved. Out of total respondents that have involved in the study, $306(37.9 \%)$ and 502(62.1\%) ever had sex and not respectively. Of the 306 respondents that ever had sex, $135(39.1 \%)$ females and 171 (56\%) were males (Table 1). Of the 304 respondents that had run-through sexual intercourse, more than half of them 168(63.36\%) also had sex in the last 12 months of campus life (Table 2).

\begin{tabular}{|c|c|c|c|c|c|c|c|c|c|c|c|c|}
\hline \multirow{3}{*}{$\begin{array}{l}\text { Gender } \\
\text { N=808 }\end{array}$} & \multirow{3}{*}{ Frequency } & \multirow{3}{*}{ Percent } & \multicolumn{8}{|c|}{ Students that Ever had sex $\mathbf{N}=\mathbf{8 0 8}$} & \multicolumn{2}{|c|}{ Total ever had sex $(\mathrm{N}=304)$} \\
\hline & & & \multicolumn{4}{|c|}{ Female } & \multicolumn{4}{|c|}{ Male } & \multirow{2}{*}{$\begin{array}{l}\text { Female } \\
133(44 \%) \\
\end{array}$} & \multirow{2}{*}{$\begin{array}{l}\text { Male } \\
171(56 \%)\end{array}$} \\
\hline & & & No & $\%$ & Yes & $\%$ & No & $\%$ & Yes & $\%$ & & \\
\hline Female & 346 & 42.8 & 211 & 60.9 & 135 & 39.1 & 291 & 63 & 171 & 37 & 304 & \\
\hline Male & 462 & 57.2 & & & & & & & & & & \\
\hline Total & 808 & 100 & & & & & & & & & & \\
\hline
\end{tabular}

Table 1. Sexual Behavior of Respondents involved in the study (Tepi Campus, 2015).

\subsubsection{Risky Sexual Behavior of Respondents}

From 304 students that ever had sex, 168 (63.36\%) of the respondents had sex in the campus in the last 12 months (Table 2). Among them 128(42.1\%) of students reported to had multiple sexual partners. In this study females were found 2.2 times more likely at risk to had sex in the campus (OR, 95\%CI;2.205(1.388-3.503, P<0.5) (Table 7). Among 304 students that ever had sex, $211(69.4 \%)$ of them never used condoms in the last 12 months of campus stay. This study also revealed that having multiple sexual partner reduce the probability of using condom by half (0.5) unit (OR, 95\%CI, .517(.295.904), $\mathrm{P}<0.05$, Table 5. In FGDs, most of the respondents indicated, some of the female students that had multiple sexual partner had sex for the welfares of grade, economic support to be non-cafe and dormitory, and to satisfy their sexual pleasure were among the reasons. Among 
students that not used condom always and consistently (211, $69.4 \%)$ in the last 12 months, $119(39.14 \%)$ and $92(30.3 \%)$

were male and female respectively (Table 2).

Table 2. Sexual Risky Behavior of students in Tepi campus (2015).

\begin{tabular}{llllllllll}
\hline \multicolumn{2}{l}{$\begin{array}{l}\text { Multiple sexual partners (two and more than two) } \\
\text { during campus life (Tepi campus) }\end{array}=\mathbf{3 0 4}$} & \multicolumn{2}{l}{$\begin{array}{l}\text { Condom Use among students who had sex in } \\
\text { MTU in the last 12 months N=304 }\end{array}$} & \multicolumn{3}{l}{$\begin{array}{l}\text { Respondents that had Sex in MTU in the } \\
\text { last 12 months N=304 }\end{array}$} \\
\hline \multirow{2}{*}{ Male } & Yes & NO & Total & Yes & No & Total & Yes & No & Total \\
& $88(29 \%)$ & $83(27 \%)$ & $171(56.2 \%)$ & $52(17.1 \%)$ & $119(39.14 \%)$ & $171(56.2 \%)$ & $109(35.9 \%)$ & $62(20.4 \%)$ & $171(56.2 \%)$ \\
Female & $40(13.2 \%)$ & $93(30.6 \%)$ & $133(43.8 \%)$ & $41(13.5 \%)$ & $92(30.3 \%)$ & $133(43.8 \%)$ & $59(64.1 \%)$ & $74(24.35)$ & $133(43.8 \%)$ \\
Total & $128(42.1 \%)$ & $178(57.9 \%)$ & $304(100 \%)$ & $93(30.6 \%)$ & $211(69.4 \%)$ & $304(100 \%)$ & $168(63.36 \%)$ & $136(44.74 \%)$ & $304(100 \%)$ \\
\hline
\end{tabular}

Table 3. Predisposing factors to HIV.

\begin{tabular}{|c|c|c|c|c|c|c|c|c|c|c|c|c|}
\hline \multicolumn{5}{|c|}{$\begin{array}{l}\text { Students that have sexual Partners outside of the } \\
\text { campus }\end{array}$} & \multicolumn{4}{|c|}{ Students that attend night dance group } & \multicolumn{4}{|c|}{ Substance use among students } \\
\hline \multirow{2}{*}{ Male } & Yes & NO & \multicolumn{2}{|l|}{ Total } & Yes & \multicolumn{2}{|l|}{ No } & Total & \multicolumn{2}{|l|}{ Yes } & No & Total \\
\hline & $59(19.41 \%$ & $112(36.8 \%)$ & \multicolumn{2}{|c|}{$171(56.3 \%)$} & $109(35.9 \%)$ & \multicolumn{2}{|c|}{$62(7.67 \%)$} & $171(21.2 \%)$ & \multicolumn{2}{|c|}{$334(41.3 \%)$} & $127(15.72 \%)$ & $462(57.2 \%)$ \\
\hline Female & $51(16.8 \%)$ & $82(27 \%)$ & \multicolumn{2}{|c|}{$133(43.7 \%)$} & $107(35.2 \%)$ & \multicolumn{2}{|c|}{$355(44.93 \%)$} & $462(57.2 \%)$ & \multicolumn{2}{|c|}{$205(25.4 \%)$} & $141(17.5 \%)$ & $346(42.8 \%)$ \\
\hline Total & $110(36.9 \%)$ & $194(63.1 \%)$ & \multicolumn{2}{|c|}{$304(100 \%$} & $214(71.1 \%)$ & \multicolumn{2}{|c|}{$417(\% 1.61 \%)$} & $808(100 \%)$ & \multicolumn{2}{|c|}{$539(66.71 \%)$} & $262(32.4 \%)$ & $808(100 \%)$ \\
\hline \multicolumn{4}{|c|}{ Hashish use behaviour of students $\mathrm{N}=808$} & \multicolumn{3}{|c|}{$\begin{array}{l}\text { Pornographic film Viewing } \\
\text { habit }(\mathrm{N}=808)\end{array}$} & \multicolumn{3}{|c|}{$\begin{array}{l}\text { STD history of students } \\
\text { Among ever had sex }(\mathrm{N}=295)\end{array}$} & \multicolumn{3}{|c|}{$\begin{array}{l}\text { Students that perceive the odds to } \\
\text { HIV in Campus }(\mathrm{N}=808)\end{array}$} \\
\hline \multirow{2}{*}{$\mathrm{Ma}$} & Yes & NO & Total & Yes & No & Total & Yes & No & Total & & Yes & NO \\
\hline & $32(4 \%)$ & $430(53.2 \%)$ & 462 & 123 & 339 & 462 & 10 & 146 & 156 & Male & 219 & 243 \\
\hline Female & $20(2.5 \%)$ & $326(40.3 \%)$ & 346 & 125 & 221 & 346 & 20 & 119 & 139 & Female & 202 & ז \\
\hline Total & $52(6.5 \%)$ & $756(93.5 \%)$ & 808 & 248 & 560 & 808 & 30 & 265 & 295 & Total & 421 & 384 \\
\hline
\end{tabular}

\subsubsection{Risk Factors to Have Multiple Sexual Partner}

Among the total respondents that had sex in MTU, $110(36.9 \%)$ and $194(63.1 \%)$ were had sexual partners outside of the campus and not respectively. Of these, 59(16.8\%) and $51(19.41 \%)$ were male and females respectively (Table 3$)$. This can be the predictor for other variable. This study showed, students that view Pornography film were 2.8 times more likely to have multiple sexual partner (OR, 95\%CI,
2.801(1.658-4.730). Students who use substances were about 1.5 times more likely to have multiple sexual partner as compared to those who don't (OR, 95\%CI, 1.502(.865-2.609) at $\mathrm{P}<0.05$. From the total of $214(71.1 \%)$ respondents that participate in group dance, $109(35.9 \%)$ were males and $107(35.2 \%)$ females. Students who attend night group dance were 1.3 times more likely to have multiple sexual partner than the counterpart (OR, 95\%CI, 1.301(.787-2.152).

Table 4. Student accommodation style (Tepi campus 2015).

\begin{tabular}{llllll}
\hline \multicolumn{5}{l}{ Students dormitory style $(\mathbf{N}=\mathbf{8 0 8})$} \\
\hline Non-café/Dormitory/both & & & & \\
Male & Female & Total & In dormitory & & Total \\
$58(7.2 \%)$ & $61(7.55 \%)$ & $119(14.73 \%)$ & Male & Female & $689(85.27 \%)$ \\
\hline
\end{tabular}

Table 5. Risk probability to have multiple sexual partner (Tepi campus 2015).

\begin{tabular}{|c|c|c|c|c|}
\hline \multirow{2}{*}{ Independent Variables } & \multirow{2}{*}{ Sig. } & \multirow{2}{*}{$\operatorname{Exp}(B)$} & \multicolumn{2}{|c|}{ 95.0\% C.I. for $\operatorname{EXP}(B)$} \\
\hline & & & Lower & Lower \\
\hline Pornography film viewing & .000 & 2.801 & 1.658 & 4.730 \\
\hline Substance use among students & .048 & 1.502 & .865 & 2.609 \\
\hline Night group dance attending & .04 & 1.301 & .787 & 2.152 \\
\hline Having sexual Partners out campus & .001 & 2.467 & 1.471 & 4.138 \\
\hline Students dormitory style (not use facility) & .044 & 1.250 & .706 & 2.216 \\
\hline HIV Risk perception in the campus & .030 & .686 & .809 & 3.517 \\
\hline Condom use during sexual episodes in the campus & .021 & 1.517 & 1.295 & 1.904 \\
\hline
\end{tabular}

Students who did not use all accommodation of the university (non-café and dormitory) 1.3 more likely to have risky sexual behavior (OR, 95\%CI; 1.250(.706-2.216). $421(52.1 \%)$ and $384(48.9 \%)$ of respondents were not perceive the risk of acquiring HIV and perceive the risk respectively. As FGD participants explained, the greater frequency of attending night group dance organized by senior students is related with higher numbers of sexual partners, substance use, sex out of condom and having sexual intercourse with more than two individuals per a time. It is 
appears to be the greater exposing factor to HIV in this campus. The odds of the result shown that risky sexual behavior likelihood of being at risk of having multiple sexual partners among students who have sexual partner outside campus were 2.5 times higher as compared to those who didn't [OR, 95\% CI, 2.467[1.471-4.138, P<0.05], table 5 .

\subsection{Risk Perception of Students}

Among respondents who perceive the risk of HIV in the campus, reduce the likely hood to have multiple sexual partners by 0.7 unit than students did not understand their environment (OR, 95\%CI; 0.686(.809-3.517) at $\mathrm{p}<0.05$ (Table 5). The findings of the qualitative study also supported the quantitative one. Majority of the key respondents and FGD participants have similar idea that sexual practice among the students is prevalent in this campus. This is in line with the quantitative data obtained from respondents. A student from engineering collage said "HIV risk perception of students is very low, for example said the discussant, students are practicing oral sex, fix sexual partner out of campus and conducting sex with ever not known person for the need of satisfaction, either economic or sex satisfaction". They were also mentioned economic and good grade desires were mentioned as a factor for sexual practice in the campus among female students. One of the female discussant mentioned, especially female students had sex mostly for seeking of money in order to full fill the needs of dressing, materials, for house rent cost, none café and ornaments with older age sexual partners like "sugar daddy". All students including females supported the idea and strengthened by saying the condition is increasing and will increase if the university never improve the facility in the campus.

\section{Discussion}

This study aimed to identify imperative information on Sexual risky behavior and Pre-exposing factors to have multiple sexual partner among Mizan-Tepi University students in Ethiopia in order to design an intervention method. Several studies documented the presence of highrisk sexual behaviors among youth in higher education institutions in Ethiopia, which might put them at high risk of HIV infection and STD.

In this study sex experience of students were examined and compared with other universities. The prevalence to sexual experience indicated in this study was 306 (37.9\%). Of $135(39.1 \%)$ were females and $171(56 \%)$ were males. This result was greater than a study conducted among students in Jimma Zone high schools and Jimma university students respectively $[14,10]$ and lower than a similar study conducted on Dilla University students [15], Tanzania students [16] and a study conducted among Addis Ababa University students [6]. Among students who experienced sex, $168(63.36 \%)$ were had sex for the last 12 months of campus life. In this study more female $(64.1 \%)$ were had sex in 12 months than female (35.9\%).

However, the finding of this study is lower than the study conducted among Jimma University students (51\%) [10]. The result from the in-depth interview and FGD disclosed the reason for having sex in the campus as unethical problem of few instructors and graduate assistants who approach female students for sex in exchange of improved grade, unfinished buildings, black spots in the campus, peer pressure and loose regulation of the university. This discussion support the quantitative result. Discussants were presented female students unwanted pregnancy during 12 months in 2013/ 2014 G.C (three female students) and in 2015/2016 G.C academic year same number as a simple existence of unprotected sex in the campus. Our study finding was showed, among 304 students that ever had sex, 211(69.4\%) of them never used condom in the last 12 months of campus stay and revealed that having multiple sexual partner reduce the probability of using condom by half $(0.5)$ unit (OR, 95\%CI, .517(.295.904), $\mathrm{P}<0.05$ (Table 5). Our study is similar with studies conducted among students of Addis Ababa university undergraduate students, Jimma University $[6,10]$ and very high than the study conducted among Haramaya University Students [17].

Substance use was a significant predictor of risky sexual behavior of students. In this study 539(66.71\%) respondents were found substance user of any type. More male 334 $(41.3 \%)$ than females $205(25.4 \%)$ were used substance. Many studies also supported this result [18]. The likely hood of substance use to have risky sex or to have multiple sexual partner was found very low (1.5 times) when compared with similar study [18]. Other studies also specified that alcohol users are almost 2 times more likely to have more sexual partner than non-users $[19 ; 20,15]$. These findings support the studies that has repeatedly shown the relationship between substance use and having multiple sexual partners [21]. This study showed lower result than a study conducted on Axum University [13].

248 respondents were watch pornography films through internet or CD and 560 were not at all. This study showed, students that view Pornography film were 2.8 times more likely to have multiple sexual partner. This study is in line with the study conducted in Jimma and Tanzania $[18,16]$. Surprisingly a study conducted in Addis Ababa university reveals alarming number of students were addicted to porno film,745(78\%) [6].The reduced number of porno viewer in our study may be due to unavailability of the access in the area.

Among students who ever had sex in the campus life, $128(42.1 \%)$ of them had multiple sexual partners $(88,29 \%)$ male and $40(13.2 \%)$ were female. This study is similar with a study conducted among students of Secondary School in Kilimanjaro, Tanzania [16] and low from study on students in Wollega University [11].

Among total respondents of this study that had sex in MTU (306), 110 (36.9\%) were had sexual partners outside of the campus. Of these, $59(16.8 \%)$ and $51(19.41 \%)$ were males and females respectively (Table 3). This result supported by FGDs and in-death interview. From the total of $214(71.1 \%)$ respondents that participate in student's night 
group dance, 109(35.9\%) were males and 107(35.2\%) females. In this study it is found that Students who attend night group dance were 1.3 times more likely to have multiple sexual partner than the counterpart, which is lower than the study conducted among Jimma university students [10]. In this study, 421 (52.1\%) and 384(48.9\%) of respondents were responded that they have no chance of acquiring HIV. and perceive the risk of gating HIV in the campus respectively. This result was very low when compared with the study conducted among Addis Ababa university undergraduate students [6].

\section{Conclusions and Recommendations}

The study revealed serious risky sexual behaviours and predisposing factors among the students, which may expose them to HIV. Almost all discussants mentioned that sexual practices by the university students were common and usually unprotected. Many girls were getting unwanted pregnancy which leads to class absenteeism and end up with school dropout. The discussants boldly mentioned that very loose university rule and regulation, peer pressure, watching pornographic movies, night group dance organized by senior students set as reasons to had risky sexual behaviour that lead to HIV infection and STD. One of the discussants said, "I think, now a day, university students had sexual intercourse by thinking that it is a fashion, moody and way of stating rejuvenation". To alleviate the problems, holistic and integrated efforts of university officials and other bodies should be politically commitment. Students should needed to give emphasise for the sensitivity and seriousness of the problem. Moreover, the finding of this study recommends to design new intervention methods or approaches to tackle the problem among university students. The university should review the existing curriculum to integrate or separately develop as a course which can be taken as sex education and HIV/STD, and provide special attention to female students life skill training.

\section{References}

[1] Mbakwem-Aniebo, C, Ezekoye, C. and. Okonko, I. Knowledge about HIV/AIDS and Reported Risk Behaviours among freshmen of the University of Port Harcourt, Port Harcourt, Southern Nigeria. World Applied Sciences Journal 2012, 16 (8): 1093-1103,

[2] United Nation Population Fund. State of World Population, People and possibilities in World of 7 billion. UNFPA, 2011.

[3] Berhane Y, Mekonnen Y, Seyoum E, Gelmon L, Wilson D. HIV/AIDS in Ethiopia an epidemiological synthesis, 2008.

[4] UNAIDS, WHO. AIDS Epidemic updates of 2009. Geneva: UNAIDS and WHO, December,2009.Available at:http://data.unaids.org/pub/report/2009/jc1700_epi_update_2 009_en.pdf

[5] EPHA. Emerging Public Health Problem in Ethiopia, Annual conference of The Ethiopian public Health association. Addis
Ababa: EPHA, 2006.

[6] Mulu Tilahun Yigzaw, Alemayehu Worku Yalew, Alemayehu Bogale Mesfin, Agumasie Semahegn Demisie. Sexual Initiation and Factors Associated with it among Addis Ababa University Undergraduate Students, Addis Ababa, Ethiopia. American Journal of Health Research, 2014, Vol. 2, No. 5, pp. 260-270. doi: 10.11648/j.ajhr.20140205.17

[7] Getnet M, Melese, T. (2008). The Drivers of HIV/AIDS Epidemic and Response in Ethiopia. Federal HIV/AIDS Prevention and Control Office, Nursery of Health April, 2008.

[8] UNICEF United Nations Children Fund, Children and AIDS Second Stock Taking Report. Plaza, New York Ny 10017, USA, 2008.

[9] Abayneh Unasho and Tarekegn Tadess..Assessment of potential risky sexual behaviors among Dilla University students: A survey study for enhancing self- protection from human immunodeficiency virus (HIV) infection.Journal of AIDS and HIV Research, 2013, Vol. 5(7), pp. 235-248.

[10] Gurmesa T, Fessahaye A, and Sisay D. Risky Sexual Behavior and Predisposing Factors amongStudents of Jimma University, Ethiopia. Ethiop J Health Sci. 2012, Vol. 22, No. 3, pp170-178.

[11] Elias Legesse. Determinants of Risky Sexual Behavior, Relation between HIV Risk Perception and Condom Utilization among Wollega University Students in Nekemte Town, Western Ethiopia. Sci. Technol. Arts Res. J., 2014, 3(3): 75-86.

[12] Dingeta, T., Oljira, L. and Assefa, N. Patterns of sexual risk behavior among undergraduate university students in Ethiopia: a cross-sectional study. The Pan African Medical Journal 2012, $12: 33$.

[13] Measho Gebreslassie, Amsalu Feleke and Tesfahun Melese. Psychoactive substances use and associated factors among Axum university students, Axum Town, North Ethiopia. BMC Public Health, 2013, 13:693.

[14] Netsanet Fentahun and Abebe Mamo.. Risky sexual behaviors and associated factors among male and female students in Jimma zone, Preparatory schools, south west Ethiopia: comparative study Ethiop J Health Sci. 2014, Vol. 24, No. 1, pp 59-68.

[15] Moges Tadesse. Substance abuse and sexual HIV-risk behaviour among Dilla University students, Ethiopia. Educational Research, 2014, Vol. 5(9) pp. 368-374.

[16] Ernest J. Karata and Stelyus L. Mkoma. Multiple Sex Partner and Risk Behavior among Secondary School Students in Kilimanjaro, Tanzania, Ethiop. J. Educ. \& Sc. 2013, Vol. 9 No. 1 PP105-114.

[17] Andualem Derese, Assefa Seme, Chalachew Misganaw. Assessment of substance use and risky sexual behaviour among Haramaya University Students, Ethiopia, Science Journal of Public Health 2014, 2(2): pp102-110.

[18] Abebe Mamo Gebretsadik, Netsanet Fentahun Babbel, Family environment and sexual behaviours in Jimma zone, south west Ethiopia, Science Journal of Public Health 2014, 2(6): 539545.

[19] Guttmacher Institute. Facts on American Youthss' Sexual and Reproductive Health January 2011, available at http://www.guttmacher.org/pubs/USTPtrends.pdf>. 
[20] Dillard, K.."Adolescent sexual behaviour. II: Sociopsychological factors." Factsheet. Washington DC, Advocates for Youth, 1996.
[21] Wang MQ, Schumacher J, Dear S, Ogunlesi D, and Cook F. Illicit Drug Use and HIV Risk Behaviors among Young African-Americans; J. Alcohol Drug Educ. 2004, pp48:7-1 5. 